\title{
Surgeon Performed Ultrasound in Assessing Thyroid Nodule Using American College of Radiology Tirads and Total Malignancy Score (TMS): A Validation Cross Sectional Study.
}

\author{
Singh $\mathbf{R}^{\mathrm{a}}$, Muhammed $\mathrm{AS}^{\mathrm{a}}$, Muhammad Latar $\mathbf{N H}^{\mathrm{a}}, \mathbf{A b d u l l a h}$ Suhaimi $\mathbf{S N}^{\mathrm{a}}$ \\ ${ }^{a}$ Department of Surgery, , Faculty of Medicine, Universiti Kebangsaan Malaysia Medical Centre, Kuala Lumpur, Malaysia.
}

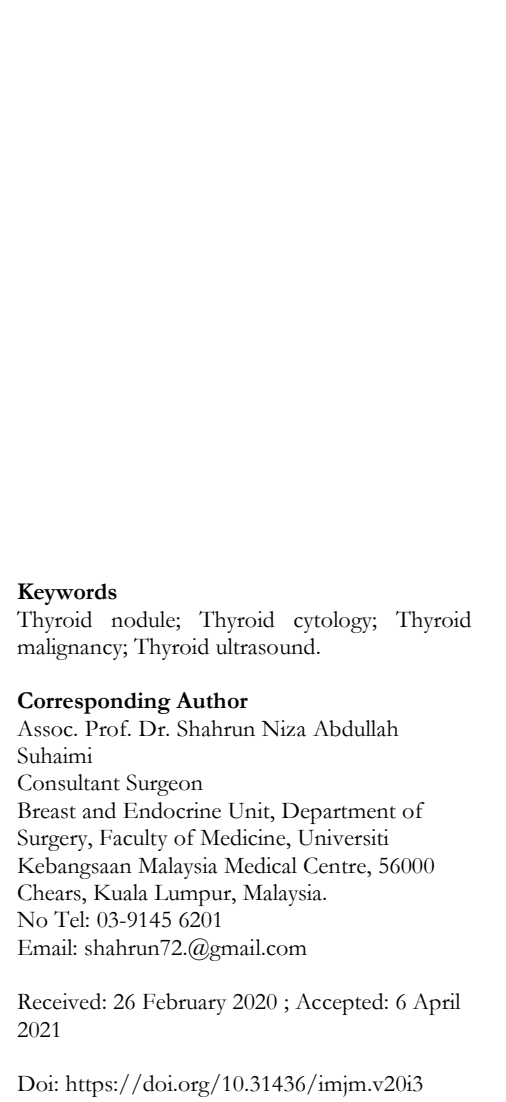

\begin{abstract}
INTRODUCTION: This study aims to evaluate the diagnostic reliability of the American College of Radiology Thyroid Imaging Report and Data System (ACR-TIRADS) and Total Malignancy Score (TMS) scoring system, in differentiating benign and malignant thyroid nodules. MATERIALS AND METHODS: This is a cross-sectional study involving patients with thyroid nodules treated at Hospital Canselor Tuanku Muhriz from October 2017 until October 2019. Ultrasound findings were scored according to the ACRTIRADS and TMS scoring system. They were then correlated with the FNAC or histopathology report. The sensitivity, specificity, positive predictive value (PPV), negative predictive value (NPV) and diagnostic accuracy of both scoring system were calculated for analysis. RESULTS: A total of 150 patients with 223 thyroid nodules were included. $17 \%$ or 38 nodules were found to be malignant. The sensitivity, specificity, PPV, NPV and accuracy of ACR-TIRADS and TMS were $97.37 \%$ vs. $84.21 \%, 52.97 \%$ vs. $62.70 \%$, $29.84 \%$ vs. $31.68 \%, 98.99 \%$ vs. $95.08 \%$ and $61 \%$ vs. $66 \%$ respectively. According to the ACR-TIRADS, only hypoechoic nodules was a strong predictor of malignancy. Comparatively, in the TMS, strong predictors of malignancy include single nodule, hypoechogenicity, irregular margin, and nodules with peri and intranodular vascularity. CONCLUSION: Both ACR-TIRADS and TMS score had good diagnostic accuracy in predicting malignant thyroid nodule. TMS is comparable and not inferior to ACRTIRADS however, the latter is more practical for use as growth and Doppler characteristic are not included in the assessment.
\end{abstract}

\section{INTRODUCTION}

Thyroid nodules are common. An estimated 19\% - 67\% of unsuspecting, healthy individuals have a detectable thyroid nodule on ultrasound. ${ }^{1}$ Fortunately, the incidence of thyroid cancer is low, between $5 \%$ to $15 \%$ in the population. ${ }^{2,3,4}$ Differentiated thyroid cancer such as papillary and follicular thyroid cancer accounts for the majority of thyroid cancer. 5 The incidence of thyroid cancer in Malaysia is 4.9/100000 populations. ${ }^{6}$

In the evaluation of a thyroid nodule, ultrasound is recommended as the first imaging tool. ${ }^{8}$ The widespread use of ultrasound has resulted in an increased rate of biopsy of thyroid nodules, commonly using the fineneedle aspiration for cytology (FNAC). ${ }^{7}$ It has become a challenge to correctly identify high-risk nodules for biopsy. Subjecting all nodules to FNAC will not only burden the health care system in terms of cost but also cause unnecessary anxiety to patients. ${ }^{8}$

Therefore, appropriate sonographic criteria are needed to accurately classify these nodules and direct decision on biopsy, as well as avoiding unwarranted procedures. An effective classification system is practical and standardised. There are many studies and classification systems formulated that categorise thyroid nodules according to the risk of cancer. ${ }^{4,8,9,10}$ Existence of many such systems has led to confusion in understanding and also raises a question about its accuracy among radiologists and clinicians.

IMJM Volume 20 No.3, July 2021 
Two thyroid ultrasound classifications evaluated in this study are the American College of Radiology - Thyroid Image Reporting and Data System (ACR- TIRADS) and the Total Malignancy Score (TMS). ACR-TIRADS was developed by the American College of Radiology in 2017 and TMS is derived by a group of radiologists in Milan since 2013. 11,12 Both of these systems use a pattern-oriented system for risk stratification and scores assigned to each feature.

The purpose of this study was to evaluate the diagnostic reliability of the Total Malignancy Score and ACRTIRADS scoring system in differentiating benign and malignant thyroid nodules. Unique to this study is that the ultrasound was performed by an endocrine surgeon and not a radiologist. In this study, we described the sub -categories of these scoring system in predicting malignant thyroid nodules, as well as comparing the accuracy of both scores.

\section{MATERIALS \& METHODOLOGY}

\section{Ethical Consideration}

Institutional review board approval was obtained for this cross-sectional study (UKM PPI/111/8/JEP-2019125).

\section{Study Population}

This study was conducted in the Breast and Endocrine surgery unit of Universiti Kebangsaan Malaysia Medical Centre, Malaysia. Patient data were collected from the hospital database of thyroid patients from October 2017 to October 2019. The inclusion criteria were patients with thyroid nodules who had undergone FNAC or thyroidectomy. Patients with inconclusive cytology were excluded.

\section{Thyroid Ultrasound}

The thyroid ultrasound scans were performed by an endocrine surgeon with more than ten years of experience, using a General Electric Logic 9 E Pro ultrasound machine (GE Healthcare, Milwaukee, WI, USA) with a linear 5-12 MHz frequency probe. A pulse repetition frequency of $2400 \mathrm{~Hz}$ and a colour gain of
40\%-50\% were used for Doppler ultrasound, performed with a linear high-frequency probe (7.5-10 MHz).

\section{Nodule Interpretation}

For ACR-TIRADS, five features of a nodule were assessed; namely echogenicity, composition, shape, margin, and echogenic foci. A score was assigned for each feature and the added total score was used to classify nodules from TR1 (benign) to TR5 (highly suspicious). This is summarised in Table I.

In TMS classification, seven parameters were assessed; namely number of the nodule (solitary or multiple), structure (colloid or solid), echogenicity, halo, calcification, margin and colour flow. Growth was not included as the data were mostly not available. Again, a score was assigned for each ultrasound feature. The total score was added, and nodule categorised as TMS $<3$, TMS $=3$ and TMS $>3$ (Table I).

\section{Data Analysis}

Statistical analysis was performed using SPSS 25.0 software (SPSS Inc., Chicago, USA). All quantitative values were expressed as the median and interquartile range (IQR). Frequencies and percentages were used to summarise the categorical data. A simple logistic regression was used to determine the association between malignant nodule with each of the ultrasound characteristic, whereas the association with patients' demographic data were estimated using the MannWhitney U test.

Multiple logistic regression was performed for ultrasound features found to be statistically significant in the simple logistic regression as predictors of the final diagnosis. Adjusted odds ratios and their corresponding 95\% confidence intervals were determined. MedCalc's online diagnostic test evaluation calculator was used to determine sensitivity, specificity and predictive values of ACR-TIRADS as well as TMS. Receiver Operating Characteristic (ROC) curve analysis and area under the curve (AUC) of TMS and ACR-TIRADS total score against malignant histopathology were determined. Statistical significance was set at $\mathrm{p}<0.05$. 
Table I: American College of Radiology Thyroid Image Reporting and Data System (ACR-TIRADS0 and Total Malignancy Score (TMS) system with their respective ultrasound feature and score.

\begin{tabular}{|c|c|c|c|c|c|}
\hline \multicolumn{3}{|l|}{ ACR-TIRADS } & \multicolumn{3}{|c|}{ Total Malignancy Score } \\
\hline Variables & Characteristics & Score & Variables & Characteristic & Score \\
\hline \multirow[t]{4}{*}{ Echogenicity } & Anechoic & 0 & \multirow[t]{3}{*}{ Number } & Multinodular & 0 \\
\hline & $\begin{array}{l}\text { Isoechoic or } \\
\text { hyperechoic }\end{array}$ & 1 & & Single Nodule & 2 \\
\hline & Hypoechoic & 2 & & & \\
\hline & Very hypoechoic & 3 & \multirow[t]{2}{*}{ Structure } & Colloid & 0 \\
\hline \multirow[t]{3}{*}{ Composition } & $\begin{array}{l}\text { Spongiform or } \\
\text { completely cystic }\end{array}$ & 0 & & & \\
\hline & Mixed solid and cystic & 1 & \multirow[t]{2}{*}{ Echogenicity } & Non-hypoechoic & 0 \\
\hline & $\begin{array}{l}\text { Solid or almost } \\
\text { completely solid }\end{array}$ & 2 & & Hypoechoic & 1 \\
\hline \multirow[t]{2}{*}{ Shape } & Wider than taller & 0 & \multirow[t]{2}{*}{ Halo } & Continuous & 0 \\
\hline & Taller than wider & 3 & & Discontinuous & 1 \\
\hline \multirow[t]{3}{*}{ Margin } & $\begin{array}{l}\text { Smooth/ } \\
\text { ill-defined }\end{array}$ & 0 & \multirow[t]{5}{*}{ Calcification } & Macrocalcification & 0 \\
\hline & Lobulated/irregular & 2 & & Microcalcification & 1 \\
\hline & Extrathyroidal & 3 & & & \\
\hline \multirow[t]{7}{*}{$\begin{array}{l}\text { Echogenic } \\
\text { foci }\end{array}$} & $\begin{array}{l}\text { None/comet tail } \\
\text { artefact }\end{array}$ & 0 & & Irregular & 2 \\
\hline & Macrocalcification & 1 & & & \\
\hline & $\begin{array}{l}\text { Peripheral/rim } \\
\text { calcification }\end{array}$ & 2 & \multirow[t]{5}{*}{ Colour flow } & Perinodular & 0 \\
\hline & \multirow{2}{*}{$\begin{array}{l}\text { Punctate } \\
\text { echogenic foci }\end{array}$} & \multirow[t]{2}{*}{3} & & Peri / intranodular & 1 \\
\hline & & & & Intranodular & 2 \\
\hline & TR 1 (benign) & 0 & & & \\
\hline & $\begin{array}{l}\text { TR } 2 \text { (not } \\
\text { suspicious) }\end{array}$ & 2 & & $\begin{array}{l}\text { (negligible or } \\
\text { no risk) }\end{array}$ & TMS $<3$ \\
\hline \multirow{3}{*}{$\begin{array}{l}\text { TIRADS } \\
\text { classification } \\
\text { based on the } \\
\text { total score }\end{array}$} & $\begin{array}{l}\text { TR } 3 \text { (mildly } \\
\text { suspicious) }\end{array}$ & 3 & \multirow{3}{*}{$\begin{array}{l}\text { TMS classification } \\
\text { based on the total } \\
\text { score }\end{array}$} & (low risk) & $\mathrm{TMS}=3$ \\
\hline & $\begin{array}{l}\text { TR } 4 \text { (moderately } \\
\text { suspicious) }\end{array}$ & $4-6$ & & $\begin{array}{l}\text { (medium or high } \\
\text { risk) }\end{array}$ & TMS $>3$ \\
\hline & $\begin{array}{l}\text { TR } 5 \text { (highly } \\
\text { suspicious) }\end{array}$ & $>7$ & & & \\
\hline
\end{tabular}

\section{RESULTS}

229 thyroid nodules were analysed from 150 patients. Six Whereas the most frequent characteristics of nodules nodules were excluded due to their purely cystic nature. on ultrasound according to the TMS were the multiple 38 nodules $(17 \%)$ were confirmed to be malignant on histopathology. The majority of patients were in their 50 's $(30.9 \%)$ and 60 's $(23.3 \%)$. The median age was 55. There were more females $(79.8 \%)$ than males (Table II). numbers of nodules $(75.8 \%)$, solid $(86.5 \%)$; anechoic, isoechoic to hyperechoic (non-hypoechoic) $(69.1 \%$ ), continuous halo (61.4\%), macrocalcification (96.4\%), regular margin $(78.5 \%)$ and perinodular Doppler colour flow $(74.9 \%)$ (Table III). Patients with TMS $<3,=3$, The most frequent ultrasound characteristics based on the ACR-TIRADS were iso or hyperechoic (nonhypoechoic) (70.4\%), solid or almost completely solid $(81.6 \%)$, wider than taller $(79.8 \%)$, smooth or ill-defined margin $(82.5 \%)$ and none or comet-tail artefact $(70.9 \%)$. When classified into TR1 to TR5, the majority of our patients fall into category TR 3 and TR 4, 32.7\% and $39.9 \%$ respectively (Table IV). and $>3$ comprised of $54.7 \%, 15.2 \%$, and $30 \%$ of the group, respectively (Table IV).

The ultrasound characteristics from both scoring systems were compared with final cytology or histology using simple logistic regression. It was noted that the median ACR-TIRADS and TMS score between benign and malignant nodule was statistically significant (Table 
III). In the ACR-TIRADS scoring system, echogenicity and shape of nodules showed a significant difference when comparing benign and malignant nodules.

Table II: Demographics of patients with thyroid nodules and their cytology or histology

\begin{tabular}{|c|c|c|c|c|}
\hline Variables & Characteristic & $\begin{array}{c}\text { Benign } \\
\text { n (\%) }\end{array}$ & $\begin{array}{c}\text { Malignant } \\
\text { n }(\%)\end{array}$ & $\overline{p \text {-value }}$ \\
\hline \multirow{6}{*}{$\begin{array}{c}\text { Age Group } \\
\text { (years) }\end{array}$} & $<30$ & $18(9.7)$ & $5(13.2)$ & \\
\hline & $30-39$ & $24(13.0)$ & $9(23.7)$ & 0.639 \\
\hline & $40-49$ & $12(6.5)$ & $2(5.3)$ & 0.577 \\
\hline & $50-59$ & $60(32.4)$ & $9(23.7)$ & 0.320 \\
\hline & $60-69$ & $44(23.8)$ & 8 (21.1) & 0.505 \\
\hline & $>70$ & 27 (14.6) & $5(13.2)$ & 0.563 \\
\hline Age (years) & Median Age & 55 & 53 & 0.153 \\
\hline \multirow[t]{2}{*}{ Sex } & Female & $154(83.2)$ & $24(63.2)$ & $<0.001$ \\
\hline & Male & $31(16.8)$ & $14(36.8)$ & \\
\hline \multirow[t]{6}{*}{ Cytology } & Bethesda I & \multicolumn{2}{|c|}{$2(2.0)$} & \\
\hline & Bethesda II & \multicolumn{2}{|c|}{$71(70.3)$} & \\
\hline & Bethesda III & \multicolumn{2}{|c|}{$6(5.9)$} & \\
\hline & Bethesda IV & \multicolumn{2}{|c|}{$7(6.9)$} & \\
\hline & Bethesda V & \multicolumn{2}{|c|}{$9(8.9)$} & \\
\hline & Bethesda VI & \multicolumn{2}{|c|}{$6(5.9)$} & \\
\hline Histology & & $185(83.0)$ & $38(17.0)$ & \\
\hline
\end{tabular}

However, when a forward stepwise logistic regression analysis was conducted, hypoechogenicity was the only independent predictor of malignancy. None of the benign nodules exhibited punctate echogenic foci and extrathyroidal extension. Both were exclusively seen in the malignant nodule. This model explains $32.5 \%$ of the variability of the histopathology results.

In the TMS score, the number of nodule, echogenicity, margin and Doppler colour pattern showed a significant difference in differentiating benign and malignant nodules (Table III). When forward stepwise logistic regression analysis was performed, single nodule, hypoechogenicity, irregular margin and peripheral/ intranodular Doppler flow, indicated strong independent predictors for malignancy. This model explains $54.3 \%$ of the variability of the histopathology results $(\mathrm{p}<0.05)$.

In the subcategories of ACR-TIRADS, malignancy risk of TR 3, TR 4, and TR 5 were $1.37 \%, 22.47 \%$ and $48.57 \%$ respectively, as opposed to nil in categories TR1 and TR2 (Table IV). When grouped into TR $<4$ and TR $\geq 4$, it was noted that TR $\geq 4$ was statistically significant in predicting a malignant thyroid nodule. TR $\geq 4$ had approximately $97.37 \%$ sensitivity, $52.97 \%$ specificity, PPV of $29.84 \%$ and NPV of $98.99 \%$ (Table IV).

The malignancy risk of TMS category $<3,=3$ and $>3$ were $4.92 \%, 5.88 \%$ and $44.78 \%$ respectively. TMS $>3$ was statistically significant in predicting a malignant nodule. When comparing TMS results and malignancy, we found that TMS 3 or more had approximately $84.21 \%$ sensitivity, $62.70 \%$ specificity, PPV of $31.68 \%$ and NPV of $95.08 \%$ (Table IV).

When using continuous data, diagnostic accuracy of TMS was similar to ACR- TIRADS, with an area under the ROC curve of 0.854 (95\% CI, 0.769 to 0.939 , $\mathrm{p}<0.001)$ and $0.824(95 \% \mathrm{CI}, 0.765$ to $0.883, \mathrm{p}<0.001)$ (Figure 1 \& Table IV).

\section{DISCUSSION}

With the common use of ultrasound, there has been an increase in the prevalence of thyroid nodules even in asymptomatic patients. ${ }^{1}$ Several studies have been carried out to identify certain ultrasound characteristics to differentiate between malignant and benign nodules. However, no one characteristic can be shown to be an absolute indicator of malignancy. ${ }^{13}$ Instead, the combination of ultrasound features predictably correlates more closely with the risk of malignancy. ${ }^{14,15,16}$

Studies have recognised several characteristics that are associated with malignancy. Taking a similar approach to the well-known breast image reporting and data system (BIRADS), thyroid imaging has been appropriately named TIRADS.8,9,14 There are many versions of the TIRADS, with the most recent one being introduced by the American College of Radiology as ACR-TIRADS in 2017.12

In 2009, Horvath et al. proposed the use of TIRADS classification to classify ultrasound features and identify nodules that will undergo FNAC. ${ }^{9}$ This was followed by a study by Park et al. with a similar aim. Both of them proposed 10 and 12 ultrasound features respectively. ${ }^{18}$ However due to its complexity, it was not widely accepted in clinical practice. These models were then 
Table III: Association of TIRADS and TMS characteristics with malignancy on histopathology.

\begin{tabular}{|c|c|c|c|c|c|c|c|c|c|}
\hline \multicolumn{5}{|c|}{ TIRADS } & \multicolumn{5}{|c|}{ TMS } \\
\hline Variables & Characteristics & $\begin{array}{l}\text { Benign } \\
\mathrm{n}(\%)\end{array}$ & $\begin{array}{c}\text { Malignant } \\
\text { n (\%) }\end{array}$ & p-value & Variables & Characteristic & $\begin{array}{l}\text { Benign } \\
\mathrm{n}(\%)\end{array}$ & $\begin{array}{c}\text { Malignant } \\
\mathrm{n}(\%)\end{array}$ & p-value \\
\hline $\begin{array}{l}\text { TIRADS } \\
\text { score }\end{array}$ & Median score & 2 & 5 & $<0.001$ & TMS & Median score & 2 & 6 & $<0.001$ \\
\hline \multirow[t]{2}{*}{ Echogenicity } & Non-hypoechoic & $143(77.3)$ & $14(36.8)$ & $<0.001$ & Number & Multiple & $155(83.8)$ & $14(36.8)$ & $<0.001$ \\
\hline & Hypoechoic & $42(22.7)$ & $24(63.2)$ & & & Single & $30(16.2)$ & $24(63.2)$ & \\
\hline \multirow[t]{4}{*}{ Composition } & $\begin{array}{l}\text { Spongiform or } \\
\text { cystic }\end{array}$ & $15(8.1)$ & $2(5.3)$ & 0.943 & Structure & Colloidal & $29(15.7)$ & $1(2.6)$ & 0.062 \\
\hline & Mixed solid cystic & $21(11.4)$ & $3(7.9)$ & & & Solid & $156(84.3)$ & $37(97.4)$ & \\
\hline & $\begin{array}{l}\text { Solid / almost } \\
\text { solid }\end{array}$ & $149(80.5)$ & $33(86.8)$ & 0.514 & & & & & \\
\hline & & & & & Echogenicity & Non-hypoechoic & $144(77.8)$ & $10(26.3)$ & $<0.001$ \\
\hline \multirow[t]{3}{*}{ Shape } & Wider than tall & $156(84.3)$ & $22(57.9)$ & $<0.001$ & & Hypoechoic & $41(22.2)$ & $28(73.7)$ & \\
\hline & Taller than wide & $29(15.7)$ & $16(42.1)$ & & & & & & \\
\hline & & & & & Halo & Continuous & $91(61.1)$ & $22(57.9)$ & 0.623 \\
\hline \multirow[t]{4}{*}{ Margin } & $\begin{array}{c}\text { Smooth or ill } \\
\text { defined }\end{array}$ & $161(87)$ & $23(60.5)$ & $\mathrm{N} / \mathrm{A}$ & & Discontinuous & $58(38.9)$ & $16(42.1)$ & \\
\hline & $\begin{array}{l}\text { Lobulated or } \\
\text { irregular }\end{array}$ & $24(13)$ & $12(31.6)$ & & & & & & \\
\hline & $\begin{array}{l}\text { Extrathyroidal } \\
\text { extension }\end{array}$ & $0(0)$ & $3(7.9)$ & & Calcification & Macro & $185(100.0)$ & $30(78.9)$ & $\mathrm{N} / \mathrm{A}$ \\
\hline & & & & & & Micro & $0(0.0)$ & $8(21.1)$ & \\
\hline \multirow{7}{*}{$\begin{array}{l}\text { Echogenic } \\
\text { foci }\end{array}$} & None or comet tail & $131(70.8)$ & $27(71.1)$ & $\mathrm{N} / \mathrm{A}$ & & & & & \\
\hline & Macrocalcification & $50(27)$ & $7(18.4)$ & & Margin & Regular & $159(85.9)$ & $16(42.1)$ & $<0.001$ \\
\hline & $\begin{array}{l}\text { Peripheral } \\
\text { calcification }\end{array}$ & $4(2.2)$ & $2(5.3)$ & & & Irregular & $26(14.1)$ & $22(57.9)$ & \\
\hline & $\begin{array}{l}\text { Punctate echogenic } \\
\text { foci }\end{array}$ & $0(0)$ & $2(5.3)$ & & & & & & \\
\hline & & & & & Colour flow & Perinodular & $150(81.1)$ & $17(44.7)$ & $<0.001$ \\
\hline & & & & & & Peri/intranodular & $21(11.4)$ & $13(34.2)$ & \\
\hline & & & & & & Intranodular & $14(7.6)$ & $8(21.1)$ & $<0.001$ \\
\hline
\end{tabular}

taken as a guide by the American College of Radiology, and in 2017 they developed the ACR-TIRADS.

In 2013, Pompili et al proposed the TMS score which classified a thyroid nodule into three risk categories:- no risk or negligible risk $(\mathrm{TMS}<3)$, low risk $(\mathrm{TMS}=3$ ) and medium or high risk (TMS $>3$ ). ${ }^{11}$ Another well-known thyroid ultrasound classification by the American Thyroid Association (ATA) in 2015, introduced high, intermediate, low and very low suspicious sonographic patterns. Each of these features carries a malignancy risk of $70-90 \%, 10-20 \%, 5-10 \%$ and less than $3 \%$ respectively. ${ }^{17}$

It recommends fine-needle aspiration biopsy (FNAB) for nodules depending on the features and size of the nodule. ${ }^{17}$ In general, nodules $<1 \mathrm{~cm}$ are not recommended for biopsy. Distinct from the ATA, both the ACR-TIRADS and TMS allocate scores to the ultrasound features and classified them with their own risk of malignancy.

In this study, ultrasound features were assessed and individual features scores were summed to obtain ACRTIRADS and TMS scores for the nodule according to Table I. The sum of ACR-TIRADS scores ranged from 0 to 14 , whereas TMS scores ranged from 0 to 11 . Both scores were compared with the definitive cytologic or histologic diagnosis.

In a multicentre analysis of thyroid nodule, there was a stepwise increase in the risk of malignancy for each point awarded by ACR TI-RADS. The published rate was; TR1: $0.3 \%$, TR2: $1.5 \%$, TR3: $4.8 \%$, TR4: 9.1\%, TR5: $35 \% .{ }^{19}$ In this study, however, malignancy risk for TR1 \& 2 were nil. TR3 had a risk of $1.37 \%$, TR4 $22.47 \%$ and TR5 $48.57 \%$. Due to its higher risk of malignancy in TR4 and TR5, we divided the classification into two, namely $\mathrm{TR}<4$ and $\mathrm{TR} \geq 4$. Overall, $T R \geq 4$ category had a sensitivity of $97.37 \%$, specificity of $52.97 \%$, positive predictive value (PPV) of 
TABLE IV: TMS and TIRADS scores and their risk of malignancy, sensitivity, specificity, PPV, NPV and accuracy.

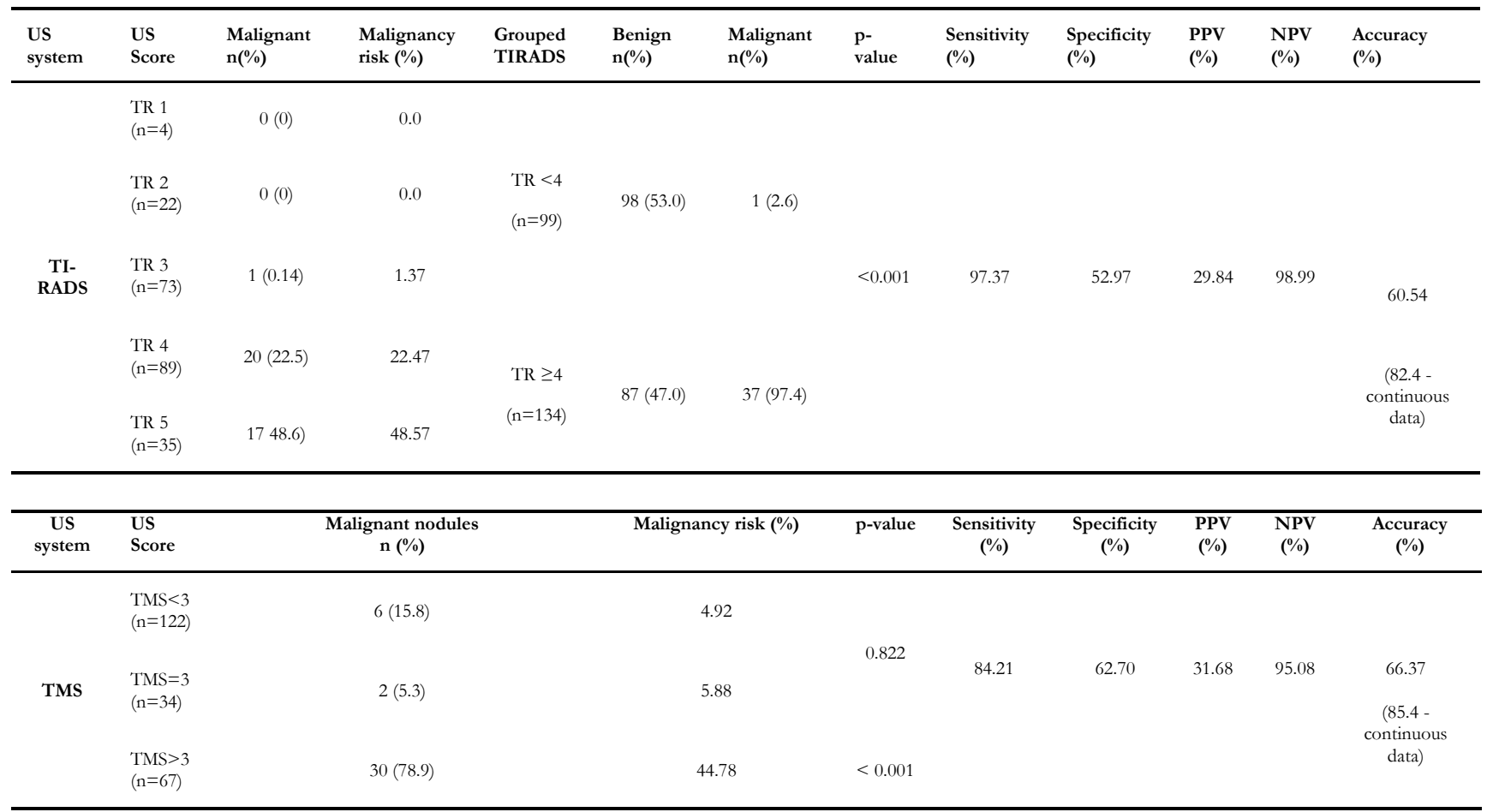

US $=$ Ultrasound, TMS $=$ Total Malignancy Score, TIRADS $=$ Thyroid Image Reporting and Data System, PPV $=$ Positive predictive value, NPV $=$ Negative predictive value.

$29.84 \%$ and negative predictive value (NPV) of $98.99 \%$ (Table IV). These findings were similar to that reported by $\mathrm{Xu}$ et al, which showed the sensitivity of $96.6 \%$, specificity of $52.9 \% \mathrm{x}$ and NPV of $95.8 \%$, however, the PPV was significantly higher in their study at $58.6 \% .^{20}$

Both the TMS and the ACR-TIRADS system showed that hypoechoic nodule was more likely to be a malignant nodule. This finding has been similarly shown in several other studies. ${ }^{8,9,10}$ However, Anil et al. in 2011 showed that although specificity was high, the sensitivity for this feature was low. Therefore, the finding of a hypoechoic nodule alone may not be sufficient to suggest malignancy. ${ }^{29}$

Pompili et al. found that hypoechogenicity, solid structure, irregular margins and the number of nodules as predictors of malignancy in TMS classification. ${ }^{21}$ Similarly in this study apart from hypoechoic features in the nodule, patients with single, irregular margins, peripheral and intranodular Doppler flow were more likely to be malignant. However, the solid or colloid structure of a nodule did not show a significant difference in detecting malignancy. The malignancy risk for $\mathrm{TMS}<3,=3$ and $>3$ were $4.92 \%, 5.88 \%$ and $44.78 \%$ respectively (Table IV). These malignancy risks were lower than the ones reported by Pompili et al in
2013. ${ }^{11}$ The overall sensitivity of TMS categories $\geq 3$ was $84.21 \%$, however, the specificity was $62.70 \%$ which is higher than that of ACR-TIRADS. Even the PPV of this study was higher as compared to the ACR-TIRADS at $31.68 \%$.

Puno-Ramos et al., in their study, showed that a nodule was 11.3 times more likely to be malignant with the presence of microcalcification. It was also noted that two or more features predictive of malignancy had a higher likelihood to be malignant on cytopathology. ${ }^{22}$ On the other hand, Smith-Bindman et al., concluded that three nodule characteristics namely microcalcification, size greater than $2 \mathrm{~cm}$ and an entirely solid composition were statistically significant in predicting thyroid malignancy. ${ }^{23}$ Remonti et al. in their meta-analysis, revealed multiple characteristics, namely solid nodule, hypoechogenicity, irregular margins, absence of halo, microcalcifications, central vascularisation, solitary nodule, heterogeneity, taller than wide shape and elasticity, all significantly associated with malignancy with an odds ratio (OR) ranging from 1.77 to 35.7. However, ultrasound has only 26.7-63\% sensitivity in predicting malignancy. Thus, they concluded that no single feature is independently reliable as a guide to decide on FNAC. ${ }^{13}$ 
Fine needle aspiration cytology has reported sensitivity between 65-98\% and specifiity between 73-100\%.24,25 Approximately $3-7 \%$ of biopsied thyroid nodule are malignant. This was similar in our study, where the confirmed malignant nodule on FNAC was 5.9\%. The malignancy rate for Bethesda $\mathrm{I}$ in published studies ranged between $1-17 \% .26$ In our study, $2.0 \%$ of the biopsied patients were classified under Bethesda I, of which all were benign on histopathology (Table II). Thus, ultrasound assessment must be used to differentiate benign from malignant to decrease unnecessary biopsy. However, there was a limitation to this, as the number of patients with Bethesda 1 who underwent surgery was small.

Overall, both systems showed good diagnostic accuracy with ACR-TIRADS and TMS showing area under the curve of 0.824 and 0.854 respectively (Figure 1). Both results are comparable with studies done by $\mathrm{Xu}$ et al and Pompili et al. ${ }^{20,21}$ This is a good yield and proves that both these systems are an effective tool for selecting patients that require FNAC. However, it should be stressed that this should be complemented with FNAC as ultrasound is only a screening tool to identify highrisk nodules.

The unique feature of both the ACR- TIRADS and TMS, when compared to other thyroid ultrasound classifications, is the ability, to sum up, the total scores of all features and classify nodules into risk-stratified groups, making it clear and easy to use and apply. Application of both these systems can potentially provide cost-saving measures to the healthcare system, achieved by a reduction in the number of unnecessary FNAC. Medical personnel managing patients with thyroid nodule must understand the rationale of using and applying either one of these scores. Also, the appropriate personnel should be trained and competent in performing thyroid US as well as able to carry out FNAC whenever necessary. From our study, we recommend that FNAC be carried out for ACRTIRADS $\geq 4$ and TMS $\geq 3$. Both these systems are applicable in our setting as both of them show good diagnostic accuracy. Thus, we leave it to the discretion of the attending physician to decide on which scoring system they prefer.

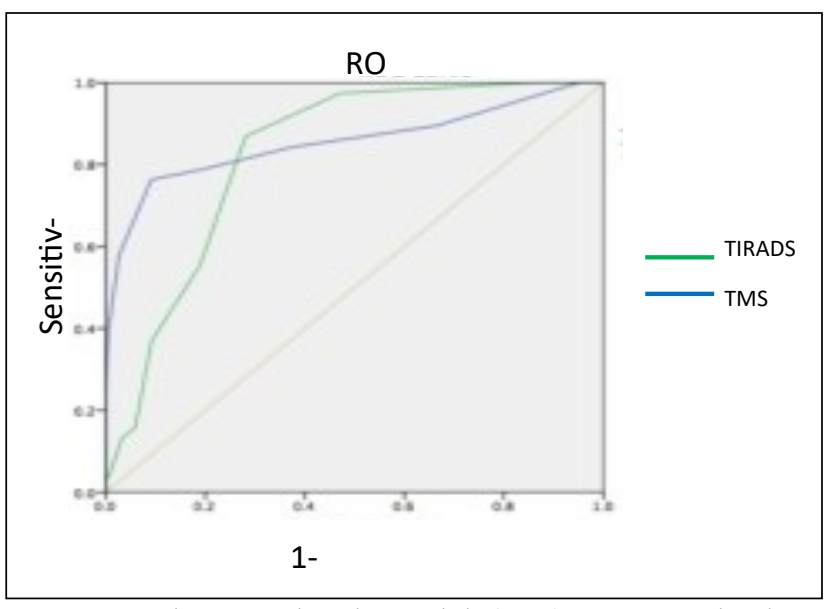

Figure 1: Receiver Operating Characteristic (ROC) curve comparing the accuracy of ACR-TIRADS and TMS

\section{STUDY LIMITATION}

This was a cross-sectional study hence there might be selection bias. Approximately $70.4 \%$ of our subjects underwent surgery due to the presence of ultrasound features suggestive of malignancy. Consequently, our malignancy rate is higher at $17.04 \%$ as compared to an FNAC based series wherein the malignancy rate is only 3 to $7 \% .^{24}$ Secondly, 71 nodules with Bethesda II were considered to be definitively benign, and no further procedures or follow-up was performed. However, this reflects clinical practice but at the expense of a possibility of the presence of false negatives among the cytology results. Moreover, it was unethically to subject patients to undergo surgery for a nodule that is highly likely to be benign for the sole purpose of obtaining histological proof. Our study population is from a single institution which might not be reflective of the entire population. To overcome this, a prospective multicentre study would be more representative.

\section{CONCLUSION}

In conclusion, both the ACR-TIRADS and TMS scoring system is useful in diagnosing thyroid nodules for malignancy. It allows for the selection of nodules with a high risk of malignancy to be subjected to FNAC, avoiding unnecessary procedures. These scores are simple, easily reproducible and reliable. TMS is comparable and not inferior to ACR-TIRADS. The latter is more practical for use as growth and Doppler characteristic is not included in the assessment. Nonetheless, either of these systems when used in an 
institution delivers uniform understanding and will help radiologists and surgeons in providing standardized treatment for patients.

\section{ACKNOWLEDGEMENT}

The authors wish to thank the Head of Department, lecturers, trainees, staff and everyone else who were either directly or indirectly involved in supporting this study throughout its course.

\section{REFERENCES}

1. Bomeli SR, LeBeau SO, Ferris RL. Evaluation of a thyroid nodule. Otolaryngol Clin North Am 2010; 43:229-38.

2. Hoang JK, Lee WK, Lee M, Johnson D, Farrell S. US features of thyroid malignancy: pearls and pitfalls. Radiographics 2007; 27:847-865.

3. Gharib H, Goellner JR. Fine-needle aspiration biopsy of the thyroid: an appraisal. Ann Intern Med 1993; 118:282-289.

4. Frates MC, Benson CB, Doubilet PM et al. Prevalence and distribution of carcinoma in patients with solitary and multiple thyroid nodules on sonography. J Clin Endocrinol Metab 2006; 91:3411-3417.

5. Davies L, Welch HG. Current thyroid cancer trends in the United States. JAMA Otolaryngol Head Neck Surg 2014; 140:317-22.

6. Ghani FA, Md Isa N, Harunarashid H, Abdullah Suhaimi SN, Sridharan R. Reliability of the ultrasound classification system of thyroid nodules in predicting malignancy. Medical Journal of Malaysia 2018; 73:9-15.

7. Moon WJ, Jung SL, Lee JH et al. Benign and malignant thyroid nodules: US differentiationmulticenter retrospective study. Radiology 2008; 247:762-770.

8. Kwak JY, Han KH, Yoon JH et al. Thyroid imaging reporting and data system for US features of nodules: a step in establishing better stratification of cancer risk. Radiology 2011; 260: 892-9.

9. Horvath E, Majlis S, Rossi R et al. An ultrasonogram reporting system for thyroid nodules stratifying cancer risk for clinical management. J Clin Endocrinol Metab 2009; 94:1748-1751.

10. Na, D.G., Baek, J.H., Sung, J.Y. et al. Thyroid imaging reporting and data system risk stratification of thyroid nodules: categorization based on solidity and echogenicity. Thyroid 2016; 26: 562-572.

11. Pompili G, Tresoldi S, Primolevo A, De Pasquale L, Di Leo G, Cornalba G. Management of thyroid follicular proliferation: an ultrasound-based malignancy score to opt for surgical or conservative treatment. Ultrasound Med Biol 2013; 39:1350_ 1355.

12. Tessler FN, Middleton WD, Grant EG, Hoang JK, Berland LL, et al. ACR Thyroid Imaging, Reporting and Data System (TI-RADS): White Paper of the ACR TI-RADS Committee. Journal of the American College of Radiology JACR 2017; 14: 587 $-595$.

13. Remonti LR, Kramer CK, Leitao CB, Pinto LCF, Gross JL. Thyroid ultrasound features and risk of carcinoma: A systematic review and meta-analysis of observation studies. Thyroid 2015; 25:538-50.

14. Xie C, Cox P, Taylor N, LaPorte S.

Ultrasonography of thyroid nodules: a pictorial review. Insights Imaging 2016; 7:77-86.

15. Adamczewski Z, Lewinski A. Proposed algorithm for management of patients with thyroid nodules/ focal lesions, based on ultrasound (US) and fineneedle aspiration biopsy (FNAB); our own experience. Thyroid Res 2013;6:6.

16. Mohammadi A, Hajizadeh T. Evaluation of diagnostic efficacy of ultrasound scoring system to select thyroid nodules requiring fine needle aspiration biopsy. Int J Clin Exp Med 2013; 6:641648.

17. Haugen BR, Alexander EK, Bible KC, et. al.. 2015 American Thyroid Association management guidelines for adult patients with thyroid nodules and differentiated thyroid cancer: The American Thyroid Association Guidelines Task Force on thyroid nodules and differentiated thyroid cancer. Thyroid 2016; 26:1-133.

18. Park JY, Lee HJ, Jang, HW, et. al. A proposal for a thyroid imaging reporting and data system for ultrasound features of thyroid carcinoma. Thyroid 2009; 19:1257-67. 
19. Middleton WD, Teefey SA, Reading CC, et al. Multiinstitutional Analysis of Thyroid Nodule Risk Stratification Using the American College of Radiology Thyroid Imaging Reporting and Data System. American Journal of Roentgenology 2017; 208: 1331- 1341.

20. Ting Xu, Ya Wu, Run-Xin Wu et al. Validation and comparison of three newly- released Thyroid Imaging Reporting and Data Systems for cancer risk determination. Endocrine 2019; 64: 299.

21. Pompili GG, Tresoldi S, Ravelli A, Primolevo A, Di Leo G, Carrafiello G. Use of the ultra-sound-based total malignancy score in the management of thyroid nodules. Ultrasonography 2018; 37:315-322.

22. Puno-Ramos MPG, Villa ML, Kasala RG, Arzadon J, Alcazaren EAS. Ultrasound features of thyroid nodules predictive of thyroid malignancy as determined by fine needle aspiration biopsy. Philipp J Intern Med 2015; 53:1-8.

23. Smith-Bindman R, Lebda P, Feldstein V et al. Risk of thyroid cancer based on thyroid ultrasound imaging characteristics: Results of a populationbased study. JAMA Intern Med 2013; 173:1788-96.

24. Cibas ES, Ali SZ, NCI Thyroid FNA State of the Science Conference. The Bethesda system for reporting thyroid cytopathology, Am J Clin Pathol 2009; 132:658-65.

25. Muratli,A, Erdogan N, Sevim, S, Unal, I, Akyuz S. Diagnostic efficacy and importance of fine-needle aspiration cytology of thyroid nodules. J Cytol 2014; 31:73-8.

26. Bongiovanni M, Spitale A, Faquin WC, Mazzucchelli L, Baloch ZW. The Bethesda system for reporting thyroid cytopathology: A metaanalysis. Acta Cytol 2012; 56:333- 9.

27. Ha EJ, Moon WJ, Na DG et al. A multicenter prospective validation study for the Korean thyroid imaging reporting and data system in patients with thyroid nodules. Korean J Radiol 2016; 17:811-21.

28. Russ G, Royer B, Bigorgne C, Rouxel A, BienvenuPerrard M, Leehardt L. Prospective evaluation of thyroid imaging and data system on 4550 nodules with or without elastography. Eur J Endocrinol 2013; 168:649-55.

29. Anil G, Hegde A, Chong FH. Thyroid nodules: risk stratification for malignancy with ultrasound and guided biopsy. Cancer Imaging 2011; 11:209-223. 